\title{
Clínica da Atividade ${ }^{1}$
}

\author{
Yves Clot
}

\begin{abstract}
Resumo
O presente artigo apresenta de forma sucinta as bases da Clínica da Atividade, a partir da discussão de temas como riscos psicossociais, saúde do trabalhador, métodos de intervenção e o papel do coletivo para a saúde do trabalhador. Apresenta os quatro registros do métier : pessoal, impessoal, interpessoal e transpessoal e explica o funcionamento do método de ação proposto pela clínica da atividade, que tem por objetivo o desenvolvimento transpessoal da função do coletivo.

Palavras-chave: clínica da atividade, saúde, métodos de intervenção
\end{abstract}

\section{Clinique de l'Activité}

\section{Résumé}

À partir d'une discussion de thèmes comme les risques psychosociaux, la santé des travailleurs, les méthodes d'intervention et le rôle du collectif dans la santé des travailleurs, cet article présente succinctement les bases de la Clinique de l'Activité. Après une présentation des quatre registres du métier (personnel, impersonnel, interpersonnel et transpersonnel), il explique le fonctionnement de la méthode d'action proposée par la clinique de l'activité, qui vise à un développement transpersonnel du collectif.

Mots-clés: Clinique de l'Activité, santé, méthodes d'intervention

\section{Introdução}

Em psicologia do trabalho, a clínica da atividade é, há quase vinte anos, uma metodologia de ação para mudar o trabalho. Ela se desenvolveu ao mesmo tempo na filiação da ergonomia* francófona e da psicopatologia do trabalho*. No âmbito mais vasto da clínica do trabalho, ela propõe meios de agir sobre as relações entre atividade e subjetividade, indivíduo e coletivo (Vygotski, 2010). Não se trata, em primeiro lugar, de uma análise do risco, quer seja ele físico ou psicológico. O interveniente ${ }^{2}$ se volta de início para ação com o intuito de desenvolver o poder de agir dos profissionais sobre seu meio de trabalho, sobre a organização e sobre si-mesmos. Trata-se menos de fazer o inventário dos riscos psicossociais, do que de encontrar, com os profissionais, os recursos psicossociais e sociais próprios para realizar um trabalho de qualidade por natureza discutível (produtos, serviços, coletivos, performances). É menos a atenção voltada ao trabalhador "exposto" aos riscos, com sua suposta passividade, do que a busca de capacidades de ação imprevisíveis em sua atividade; é menos a preocupação de promover o suposto "bem-estar" do operador, do que a preocupação de redescobrir, com ele, os prazeres do "bem-fazer". Pois aqui se encontra a mola propulsora da saúde no trabalho.

A saúde, longe de ser reduzida à ausência de doença ou mesmo a uma satisfação mostrada, pode ser definida como Winnicott: "A vida de um indivíduo saudável se caracteriza tanto pelos medos, pelos sentimentos conflituosos, pelas dúvidas, pelas frustrações quanto pelos aspectos positivos. $\mathrm{O}$ essencial é que o homem ou a mulher se sinta viver sua própria vida, tomar a responsabilidade de sua ação ou de sua inação, se sinta capaz de se atribuir o mérito de um sucesso e a responsabilidade de um fracasso" (1988, p. 30). Saúde e poder de agir têm, portanto, uma ligação naqueles que trabalham. Sem estar - ao menos de tempos em tempos - na origem do que lhe acontece, o trabalho se torna rapidamente insustentável aos seus próprios olhos. No entanto, o que lhes cabe fazer é cada vez mais desatado daquilo que conta realmente para eles. Sua própria atividade é, então, desafetada. Pode-se, dessa forma, perder a saúde antes mesmo de ficar doente. A passividade que se impõe aos sujeitos diminuídos por um "trabalho nem feito, nem a fazer" envenena uma existência profissional abortada. É no encontro da atividade contrariada que se coloca uma clínica da atividade a serviço do trabalho.

\section{Riscos psicossociais e qualidade do trabalho}

Duas abordagens estão presentes: uma primeira parte da exposição dos assalariados aos riscos psicossociais já identificados. Uma segunda, apresentada aqui, se liga um outro tipo de

\footnotetext{
*Endereço eletrônico: yves.clot@ lecnam.net
} 
exposição: à exposição da qualidade do trabalho aos dilemas da atividade real em cada situação. Dessa forma, o psicossocial não é necessariamente um risco. Ele pode se tornar o objeto de uma atividade deliberada, fonte potencial da vitalidade social e organizacional, um recurso a desenvolver.

Pode-se resistir a uma tentação frequente nas organizações: a de requalificar as situações de trabalho "frágeis" ou "quebradiças", saturadas de problemas não resolvidos, em fragilidade pessoal, imputada àqueles que toleram pouco essas situações críticas. A tentação de reformar os comportamentos em vez de transformar o trabalho conduz a querer "reparar" os trabalhadores para purgar o real destes conflitos. A gestão atual dos riscos psicossociais cede demasiadamente a essa tentação higienista. $\mathrm{O}$ problema social é, então, traduzido na linguagem do risco sanitário. Classifica-se como "sujeitos fracos" aqueles que insistem em preservar a ideia que fazem - com ou sem razão - do trabalho bem feito. Alguns indícios utilizados nos planos de ação contra os riscos psicossociais despistam a "pesquisa obsessiva da perfeição" nos operadores muito minuciosos, presos às ideias fixas de uma "super qualidade" que não lhes é mais exigida. Fonte de conflitos na organização, essa "conduta de risco" é vista como uma patologia da vontade de cuidar. Muitos planos de ação contra os riscos psicossociais adicionam então a gestão dos riscos aos riscos da gestão, estendendo o domínio do gerenciamento, por sua vez, à engenharia psicológica. É o estresse* dos assalariados que é preciso então tratar, ao passo que é o trabalho em si que está doente, já que eles não podem cuidar dele. Essa "psicologia", que transforma a escuta do sofrimento em ação adaptativa, toca ligeiramente na obrigação de cuidado (Clot, 2010). É o contrário de uma clínica da atividade da qual vamos, agora, descrever o objetivo e a metodologia.

Sua essência é simples. Trata-se de apoiar o relançamento de um trabalho cuidado no seio de organizações que o pedem e para atingir objetivos que ultrapassam tais organizações: em nome da saúde no trabalho dos assalariados, claro, mas também em nome da saúde pública. Levar em consideração a qualidade do trabalho é um recurso possível contra a proliferação dos produtos tóxicos no mercado, a pobreza de certos serviços, ou, ainda, a multiplicação de escândalos sanitários. Dado central para a saúde dos trabalhadores, o trabalho cuidado é um aliado da saúde fora do trabalho. Engajando primeiro as empresas, ele concerne também os usuários e os consumidores. A qualidade é uma demanda elevada em toda a sociedade. Uma clínica das atividades profissionais não abarca toda a questão. Mas, dentro do trabalho, ela participa da regeneração de um profissionalismo "deliberado" propício à saúde. $\mathrm{O}$ profissionalismo é um elemento chave do reconhecimento. No trabalho, não é suficiente ser reconhecido por alguém. É preciso, ainda, se reconhecer em algo: uma história comum, um produto, uma técnica, uma linguagem, uma marca, um métier ${ }^{3}$, uma trajetória. Sem esse "algo" que propicia um mínimo de orgulho, é muito difícil "ser alguém".

\section{Disputa profissional}

Os trabalhadores não são naturalmente predispostos ao trabalho "bem feito". Os critérios reais deste último são, aliás, mais difíceis de definir no trabalho de serviço. Para defender os métiers, é preciso atacar esse problema. Um profissionalismo ampliado supõe, entre assalariados, a instrução da "controvérsia profissional" sobre os critérios do trabalho de qualidade. O "debate de escolas" é a condição da existência de um coletivo de trabalho, pois permite civilizar o real que multiplica os inevitáveis inesperados e divide facilmente aqueles que trabalham. Uma responsabilidade do ato profissional pode sair daí e desemboca na possibilidade de ter autoridade dentro do seu trabalho, estado propício à saúde mental. Mas essa "controvérsia profissional" não pode ser privilégio dos operadores. Por esse motivo, os empregadores não são mais espontaneamente orientados à qualidade do trabalho. $\mathrm{O}$ conflito inerente à relação salarial, hoje amplamente envenenado na França, tornou-se muito pobre, arrefecido nos papéis assumidos. Podemos enriquecê-lo pela experimentação de uma conflitualidade instruída e negociada sobre a qualidade do trabalho entre assalariados e direção.

Certamente, a controvérsia social sobre o trabalho bem feito não tem respaldo oficial dentro da empresa. Mas a experiência de uma clínica da atividade nas organizações que encomendam esse trabalho mostra que se pode instituir o conflito, fazendo recuar o velho hábito de trapacear com o real dentro das organizações. A negação do conflito corriqueiro - considerando-o normal - sobre o trabalho bem feito intoxica hoje as relações sociais e as desvitaliza, degradando a saúde no trabalho. A repressão dessa dissonância flagrante, que 
entretanto existe, é o principal risco psicossocial do período. Uma clínica da atividade tem por objeto levantar essa inibição dialógica pela retomada da criação profissional coletiva. $\mathrm{O}$ profissionalismo tem necessidade de diálogo para sobreviver, de discordâncias e de compromissos. Quando a paralisia do diálogo profissional sobre as verdades do trabalho ganha o métier, este último se endurece e se fragiliza na atividade de cada um e na organização inteira. As energias são dissipadas e os recursos desperdiçados. A inteligência e o engajamento subjetivo e coletivo só se aguçam escutando e deliberando; é estudando profundamente o problema, examinando todas as soluções, que se encontra aquelas que se busca, sobre as quais uma unanimidade ao menos provisória pode se fazer e que ninguém tinha considerado antes. Sem poder se deixar afetar pelas surpresas deste diálogo sobre o trabalho concreto, tornamo-nos cegos.

A negação do conflito sobre a qualidade do ato não é saudável. O profissionalismo sente isso e o desenvolvimento do métier*, reprimindo suas contradições, perde suas possibilidades, pois o dinamismo profissional está enraizado nas objeções do real e nos conflitos que ele suscita. Não se trata de chegar à sacrossanta "boa prática" por trás da qual nos organizamos em fila indiana. Uma das principais contribuições do tipo de clínica que fazemos, quando conseguimos fazer um bom trabalho, é que, concretamente, a qualidade do trabalho é, por natureza, definitivamente discutível. E nessa perspectiva, o que não compartilhamos é ainda mais interessante do que aquilo que já compartilhamos. A única boa prática é, sem dúvida, a prática da controvérsia profissional entre "conhecedores", depois entre estes e a linha hierárquica. Este é o sentido de uma clínica da atividade preocupada com o métier.

\section{Um métier, quatro registros}

Um métier é primeiramente um paradoxo: ele não pertence a ninguém e, entretanto, cada um é responsável diante das sanções da prática. O métier é uma espécie de instituição com várias vidas simultâneas e é isso que torna possível seu desenvolvimento na organização, e mesmo além da organização, na sociedade. Ele tem uma arquitetura: no sentido mais próximo do real, é primeiramente o gesto pessoal próprio de cada um que nos faz dizer que alguém tem o métier. Mas, no trabalho, não há "solo". colegas destinatários dos esforços consentidos. O métier é nesse aspecto interpessoal. Ele vive, então, ou morre, entre os profissionais e, em cada um deles, na motricidade das trocas pessoais e interpessoais sobre o que há a fazer ou a refazer, a dizer ou a re-dizer, sobre o que precisaria ou se precisará fazer. Essa gramática da ação mostra até que ponto o métier é uma conjugação. Ele não é todo inteiro no presente das atividades compartilhadas na situação. Estas precisam de antecedentes que permitam se colocar no diapasão da ação: é a história e a memória coletiva que dão a cada um a garantia para agir no presente e "ver chegar" o futuro. Essa memória é transpessoal, ninguém é seu proprietário. Disponível a todos quando ela existe, ela atravessa as gerações e cada profissional individualmente. É o teclado coletivo dos gestos e das palavras, sobre o qual cada sujeito pode tocar sua pequena música, o gênero profissional a ser estilizado por cada um. Instituído, mas sempre potencialmente defunto, organizado por subentendidos ou por enigmas, esse gênero é um traço de união que sempre corre o risco de se apagar, se não for refeito no curso das atividades interpessoais e pessoais.

Além disso, o métier não é instituído somente na memória coletiva transpessoal. Ele existe também, impessoal, registrado nas funções oficiais prescritas. É uma carreira, uma aposentadoria, deveres, status, formação, critérios de avaliação e de recrutamento, indicadores padronizados de performance, enfim um outro mundo além daquele da atividade em situação ou da história coletiva implícita. Ele é depositado nos recursos humanos e no mercado de trabalho. É a aparelhagem mais afastada da atividade concreta. No contato com esse registro, cada um se sente substituível. Mas esse métier impessoal é psicologicamente vital para imaginar o que podemos nos tornar ou não, o que poderíamos fazer além daquilo que já fazemos.

As tensões se insinuam em todas as direções nessa arquitetura até, às vezes, fazê-la explodir. Pois o métier reune - nas discordâncias criativas ou destrutivas - esses quatro registros: impessoal, transpessoal, interpessoal e pessoal. Ele não está sempre vivo pelas mesmas razões, nem no mesmo ambiente. Morto em uma ponta, ele pode ressuscitar em outra. Ele não é inteiro em lugar nenhum, nem na atividade, nem na tarefa, nem no coletivo. Vivo, ele transita em todos os lugares 
sobre fronteiras flutuantes. Morto em um registro, ele explode o conjunto da instituição. Qualquer um que pretenda encarná-lo exclusivamente o perde e o usurpa. É um ponto de fuga do qual nenhum indivíduo, nenhuma organização, e nenhum coletivo pode se apropriar. O paradoxo desse desequilíbrio irredutível deveria submeter todos os protagonistas envolvidos às exigências da retificação. A saúde depende disso: fica a cargo de cada profissional com seus colegas manter essa arquitetura no contato das surpresas do real, de norteá-la pelo que a sustenta em pé: a qualidade do trabalho para sempre discutível. Fazer seu métier, é talvez ter sucesso ou fracassar em cuidar dessa arquitetura, pois os recursos psicossociais não são interpostos todos no mesmo local e, no entanto, merecem serem sempre cultivados em todos os lugares.

No entanto, não sejamos inocentes. Nessa arquitetura, tudo está ligado, mas tudo é frequentemente desligado pelos antagonismos considerados irredutíveis. No trabalho, o sentimento de viver a mesma história pode se apagar deixando caminho livre às brigas entre as pessoas. Um métier sem resposta transpessoal pode degenerar um face à face raivoso entre um exercício pessoal solitário e injunções impessoais fictícias. Uma verdadeira despersonalização do trabalho se segue. É no defronte dessa dissociação ameaçadora que se porta a ação em clínica da atividade cujas três grandes fases metodológicas descreveremos aqui.

\section{Método para a ação}

Na primeira fase, em resposta à comanda de uma direção, de um comitê de higiene, de segurança e das condições de trabalho* ou de um comitê de empresa, organiza-se a instância dialógica, em que o conflito sobre a qualidade do trabalho poderá ser instruído entre os representantes do pessoal, os responsáveis estratégicos e os encarregados da saúde. É o primeiro nível de experimentação. O trabalho, nesse quadro, supõe a instrução do dossiê a partir das situações corriqueiras analisadas primeiramente pelos coletivos de profissionais envolvidos na "primeira linha". Esses profissionais "do chão de fábrica", conhecedores do métier, são chamados a participar diretamente, o mais cedo possível, dessa instância de diálogo, em que várias reuniões são previstas com encontros periódicos. A segunda fase, que é a mais longa da intervenção, se relaciona ao engajamento dos profissionais do chão de fábrica no trabalho coletivo sobre as atividades corriqueiras a serem transformadas. Nesse momento, o principal é a demanda desses profissionais, a qual se refere sempre, de alguma forma, à saúde deles. Esse tempo de duração da intervenção é o tempo da controvérsia profissional entre os conhecedores, sem participação da hierarquia. É o tempo do trabalho coletivo acerca dos prazeres e desprazeres da controvérsia sobre o trabalho bem feito. Dois métodos são utilizados, as autoconfrontações, a partir de dados em vídeos, ou as instruções ao sósia (CLOT, 2008). Ambas querem desenvolver a função psicológica do coletivo para imaginar novas possibilidades de pensar e de agir. Na terceira fase, os resultados produzidos (versão em vídeo ou versão em papel) pelos profissionais sobre suas controvérsias se tornam objeto de um outro diálogo instituído no seio da instância inicial. O coletivo muda de local no decorrer da intervenção, tornando-se fonte para modificar a organização do trabalho. $\mathrm{O}$ círculo da controvérsia profissional se amplia. Ela se enriquece com novos objetos. A intervenção tinha por objetivo o desenvolvimento transpessoal do métier na segunda fase. Ao encontrar os sindicatos e a direção, os resultados potenciais desse primeiro desenvolvimento adquirem o status de meio para um outro objetivo: o desenvolvimento impessoal do métier na organização.

Na realidade nada é tão linear e as fases da ação se encavalam. Mas, o conjunto da intervenção é concebido como um desenvolvimento transpessoal da função do coletivo: função psicológica como recurso para que cada profissional personalize ainda mais sua própria atividade; função social como recurso para que a organização transforme o registro impessoal do métier. A arquitetura desse último é "testada" para que cada um dos registros, após ser melhor diferenciado, torne-se um instrumento regenerado da atividade corriqueira. A restauração da conflitualidade profissional não é adquirida de antemão. A última palavra nunca é dita. Mas, se a retomada do trabalho de organização aconteceu, a saúde pode sair dali amadurecida.

\section{Notas}

1 Esta é uma versão atualizada, do capítulo originalmente publicado em francês no livro: Zawieja, P. e Guarnerie, F. Dictionnaire des risques psychosociaux. Paris: Ed. Seuil, 2014. Traduzido nesta revista por Suélen Maria Rocha e Emily Caroline da Silva, doutorandas do 
programa de Estudos linguísticos, literários e tradutológicos de francês da FFLCH/USP e integrantes do grupo de pesquisa ALTER-AGE$\mathrm{CNPq}$ e revisado pela Profa. Dra. Eliane Gouvêa Lousada, professora do programa de Estudos linguísticos, literários e tradutológicos de francês da FFLCH/USP e líder do grupo de pesquisa ALTER-AGE-CNPq.

2 [Nota das tradutoras]: Em francês, "intervenant" é a pessoa que realiza o trabalho de clínico da atividade, conduzindo as atividades de confrontação e coanálise da situação de trabalho, descritas na metodologia. Optamos por traduzir aqui por "interveniente".

3 [Nota das tradutoras]: Em francês "métier" corresponde ao ofício, à profissão, ao trabalho que se realiza. Neste texto, optamos por manter o termo "métier", por se tratar de um termo com o qual os estudiosos da área da Clínica da Atividade já estão familiarizados.

4 [Nota das tradutoras]: no sentido de solo musical.

\section{Referências}

CLOT, Y. (2008) Travail et pouvoir d'agir. Paris, PUF.

CLOT, Y (2010) Le Travail à cour. Pour en finir avec les RPS. Paris, La Découverte.

VYGOTSKI, L. S. (2010) Signification historique de la crise en psychologie. Paris, La Dispute.

WINNICOTT, D. (1988) Conversations ordinaires. Paris, Gallimard.

\section{Sobre o autor:}

Yves Clot é professor colaborador no Conservatoire National des Arts et Métiers (CNAM) em Paris, e integra o Laboratoire de Psychologie de Travail desta instituição, na qual, a partir de sua entrada, organizou-se a equipe de Clínica da Atividade.

Recebido em julho de 2017.

Aprovado em novembro de 2017. 